\title{
RESEARCH
}

Open Access

\section{Plasma biomarkers for amyloid, tau, and cytokines in Down syndrome and sporadic Alzheimer's disease}

Carla M. Startin ${ }^{1,2,3^{*}}$ (D), Nicholas J. Ashton ${ }^{4,5,6,7}$, Sarah Hamburg ${ }^{1,2,3}$, Rosalyn Hithersay ${ }^{1,2,3}$, Frances K. Wiseman ${ }^{3,8}$, Kin Y. Mok ${ }^{3,9,10}$, John Hardy ${ }^{3,9,11}$, Alberto Lleó ${ }^{12}$, Simon Lovestone ${ }^{13}$, Lucilla Parnetti ${ }^{14}$, Henrik Zetterberg ${ }^{6,8,15,16}$, Abdul Hye ${ }^{4,5}$, LonDownS Consortium and André Strydom ${ }^{1,2,3}$

\begin{abstract}
Background: Down syndrome (DS), caused by chromosome 21 trisomy, is associated with an ultra-high risk of dementia due to Alzheimer's disease (AD), driven by amyloid precursor protein (APP) gene triplication. Understanding relevant molecular differences between those with DS, those with sporadic AD (SAD) without DS, and controls will aid in understanding AD development in DS. We explored group differences in plasma concentrations of amyloid- $\beta$ peptides and tau (as their accumulation is a characteristic feature of AD) and cytokines (as the inflammatory response has been implicated in AD development, and immune dysfunction is common in DS).

Methods: We used ultrasensitive assays to compare plasma concentrations of the amyloid- $\beta$ peptides $A \beta_{40}$ and $A \beta_{42}$, total tau (t-tau), and the cytokines IL1 $\beta, I L 10, I L 6$, and TNFa between adults with DS ( $n=31)$, adults with SAD ( $n=27)$, and controls age-matched to the group with DS $(n=27)$, and explored relationships between molecular concentrations and with age within each group. In the group with DS, we also explored relationships with neurofilament light (NfL) concentration, due to its potential use as a biomarker for AD in DS.

Results: $A \beta_{40}, A \beta_{42}$, and IL1 $\beta$ concentrations were higher in DS, with a higher $A \beta_{42} / A \beta_{40}$ ratio in controls. The group with DS showed moderate positive associations between concentrations of t-tau and both $A \beta_{42}$ and ILI $\beta$. Only NfL concentration in the group with DS showed a significant positive association with age.

Conclusions: Concentrations of $A \beta_{40}$ and $A \beta_{42}$ were much higher in adults with DS than in other groups, reflecting $A P P$ gene triplication, while no difference in the $A \beta_{42} / A \beta_{40}$ ratio between those with $D S$ and SAD may indicate similar processing and deposition of $A \beta_{40}$ and $A \beta_{42}$ in these groups. Higher concentrations of IL1 $\beta$ in DS may reflect an increased vulnerability to infections and/or an increased prevalence of autoimmune disorders, while the positive association between IL1 $\beta$ and t-tau in DS may indicate IL1 $\beta$ is associated with neurodegeneration. Finally, NfL concentration may be the most suitable biomarker for dementia progression in DS. The identification of such a biomarker is important to improve the detection of dementia and monitor its progression, and for designing clinical intervention studies.
\end{abstract}

Keywords: Down syndrome, Alzheimer's disease, Dementia, Biomarker, Plasma, Amyloid, Tau, Interleukin 1ß, Cytokines

\footnotetext{
* Correspondence: carla.startin.09@ucl.ac.uk

'Department of Forensic and Neurodevelopmental Sciences, Institute of

Psychiatry, Psychology and Neuroscience, King's College London, 16 De

Crespigny Park, London SE5 8AF, UK

${ }^{2}$ Division of Psychiatry, University College London, London, UK

Full list of author information is available at the end of the article
}

(c) The Author(s). 2019 Open Access This article is distributed under the terms of the Creative Commons Attribution 4.0 International License (http://creativecommons.org/licenses/by/4.0/), which permits unrestricted use, distribution, and reproduction in any medium, provided you give appropriate credit to the original author(s) and the source, provide a link to the Creative Commons license, and indicate if changes were made. The Creative Commons Public Domain Dedication waiver (http://creativecommons.org/publicdomain/zero/1.0/) applies to the data made available in this article, unless otherwise stated. 


\section{Background}

Down syndrome (DS) is associated with an ultra-high risk of developing dementia caused by Alzheimer's disease (AD) [1]. The lifetime dementia risk in DS is in excess of $95 \%$, with a median age of onset of 55 years $[2,3]$, and the majority of adults with DS who die after the age of 36 have a diagnosis of dementia [4]. DS is caused by chromosome 21 trisomy and is the most common genetic cause of intellectual disability, with a UK incidence of approximately 1 in 1000 live births [5]. AD in DS is driven by the overexpression of genes on chromosome 21 due to their triplication, with triplication of the amyloid precursor protein $(A P P)$ gene being of particular importance. The amyloid precursor protein encoded by the APP gene is cleaved by $\beta$ and $\gamma$ secretases to form amyloid- $\beta$ (A $\beta$ ) peptides, with $A \beta_{42}$ the main component of the $A \beta$ plaques characteristic of $A D$ [6]. Such $A \beta$ deposits are found in the brains of adults with full trisomy 21 by the mid-30s [1, 7]. Further, familial mutations in, or duplications of, the APP gene cause early-onset AD independent of DS $[1,8]$, and individuals with a partial trisomy of chromosome 21 not including $A P P$ do not develop AD or show $\mathrm{A} \beta$ pathology $[9,10]$. Triplication of the APP gene and the subsequent overproduction of $A \beta$ peptides are therefore likely to be central to the development of AD in people with DS, and DS may be considered a genetic cause of AD.

The presence of $A \beta$ plaques in both sporadic $A D$ (SAD) without DS and in people with DS, with the high risk of dementia in DS, indicates their development is a key component of the development of AD. Indeed, the amyloid hypothesis of $\mathrm{AD}$ states the presence of $\mathrm{A} \beta$ plaques initiates a cascade of events that leads to cell death and cognitive decline $[11,12]$. Other pathophysiological mechanisms are also important within this cascade.

Firstly, the development of neurofibrillary tangles, composed of hyperphosphorylated and misfolded tau protein, is another neuropathological feature of $\mathrm{AD}$. There is a stronger association between cognitive decline and tau pathology than with $A \beta$ plaques in both DS [13] and SAD [14]. Secondly, neuronal damage within the brain can be measured by the release of neurofilament light (NfL), a scaffolding cytoskeleton protein, into plasma in a number of neurodegenerative disorders including SAD [15] and AD in DS [16, 17]. Finally, the inflammatory response is of interest as a potential contributory molecular mechanism to the development of $\mathrm{AD}$. In $\mathrm{SAD}$, the role of the immune system is supported by epidemiological and genetic studies. The presence of systemic infections and increased blood (plasma or serum) concentrations of cytokines including interleukin $1 \beta$ (IL1 $\beta)$, interleukin 10 (IL10), interleukin 6 (IL6), and tumour necrosis factor $\alpha$ (TNF $\alpha$ ) have been associated with SAD and predict cognitive decline
[18-22]. Genome-wide association studies of sAD have implicated several genes involved in immune function (including variants in $C L U, A B C A 7, C R 1$, and CD33) [23-25], and there is an over-representation of genetic associations with sAD in pathways involved in the innate immune response [26].

To fully understand the development of $\mathrm{AD}$ in $\mathrm{DS}$, it is therefore important to understand relevant molecular differences between those with DS, those with SAD, and controls. Similarities and group differences in plasma concentrations of molecules associated with $\mathrm{AD}$ and relationships between these possible biomarkers, in particular $A \beta$ peptides and tau, may help to identify markers of AD progression. Previous studies comparing plasma concentrations of $\mathrm{A} \beta$ peptides and tau in individuals with DS to age-matched controls have reported increased concentrations of $A \beta_{40}$ and $A \beta_{42}$ [17, 27-37] and total tau (t-tau) $[28,38]$ in DS. Results regarding the $\mathrm{A} \beta_{42} / \mathrm{A} \beta_{40}$ ratio are less consistent; while several studies have reported this to be lower in those with DS [28, 30, 31 ], others have reported this to be higher [33] or to show no difference [29] relative to controls. To date, few studies have compared plasma concentrations of $A \beta$ peptides and tau in adults with DS to those with SAD. Two studies have reported increased $A \beta_{40}$ and $A \beta_{42}$ in those with DS $[29,36]$, while another study reported lower concentrations of both $\mathrm{A} \beta_{42}$ and t-tau in adults with DS [28] compared to individuals with SAD.

In addition, a potential involvement of the immune system in the development of AD is of particular interest in DS due to immune dysfunction being common in DS, with an increased vulnerability to some types of infections throughout life [39] and higher rates of autoimmune disorders [40] in DS. Further, in DS, there is an overexpression of immune genes found on chromosome 21 (such as IFNAR1, IFNAR2, and IFNGR2, which all encode interferon- $\gamma$ (IFN- $\gamma$ ) receptor proteins) [41]. In adults and children with DS, higher blood (plasma or serum) concentrations of IL10 [31, 42], IL6 [31, 43, 44], and TNF $\alpha[31,43,45]$ have been reported compared to age-matched controls, although lower concentrations of IL10 [45], IL6 [42], and TNF $\alpha$ [42] in DS have also been reported. A recent meta-analysis of 19 cytokine studies in adults and children with DS suggested that IL1 $\beta$, TNF $\alpha$, and IFN- $\gamma$ (but not IL6 or IL10) concentrations are raised by trisomy 21 [46].

Further studies using newly developed ultrasensitive assays are therefore needed to better understand differences in concentrations of $\mathrm{A} \beta$ peptides, tau, and cytokines in individuals with $\mathrm{DS}, \mathrm{SAD}$, and controls. We therefore compared plasma concentrations of $A \beta_{40}$, $\mathrm{A} \beta_{42}$, t-tau, IL1 $\beta$, IL10, IL6, and TNF $\alpha$ between adults with DS, adults with SAD, and controls age-matched to the group with DS (to determine the effect of triplication 
of chromosome 21), and explored relationships between molecular concentrations within each group. Given the universal development of AD pathology in those with DS and increased risk of dementia with increased age [2], we also explored relationships between molecular concentrations and age. In addition, in the group with DS, we explored relationships with concentrations of NfL. Our group and others have previously shown NfL to be a potential biomarker for AD in DS, with higher $\mathrm{NfL}$ concentration associated with increased age and dementia development $[16,17]$, and so molecular concentrations that correlate with NfL may be particularly informative.

\section{Methods}

\section{Participants}

Adults in the group with DS ( $n=31$, including 7 with a clinical diagnosis of dementia) were recruited as a part of the LonDownS Consortium's studies in adults with DS [47]. Clinical diagnoses of dementia were made by each individual's clinician after a comprehensive clinical assessment. Participants were included in the present study if they lived within travelling distance of London to allow processing time for the blood sample, and they agreed to have a blood test. The presence of an additional chromosome 21 was confirmed genetically using saliva or blood samples; following DNA extraction, genome-wide single nucleotide polymorphism genotyping was performed using an Illumina OmniExpressExome array (San Diego, CA, USA) at UCL Genomics, then assembled and visually inspected in GenomeStudio. All adults were observed to have trisomy 21, with clinical notes from two individuals confirming this was due to a translocation.

For adults with DS, ethical approval was obtained from the North West Wales Research Ethics Committee (13/ WA/0194). Where individuals had the capacity to consent for themselves, we obtained written informed consent. Where individuals did not have the capacity to consent, a consultee was asked to approve the individual's inclusion based on their knowledge of the individual and his/her wishes, in accordance with the UK Mental Capacity Act 2005.

Adults in the SAD and control groups $(n=27$ per group) were recruited from the multi-centre consortium European Medical Informatics Framework (EMIF) [48]. All plasma samples used in this study were from two sites (Clinica Neurologica, Universita di Perugia, and Hospital de la Santa Creu i Sant Pau, Barcelona). All participants in the SAD group had an AD diagnosis according to standard criteria [49], and biological AD was also confirmed using concentrations of cerebrospinal fluid (CSF) $A \beta_{42}$ with a cutoff value indicating $A D$ $(<800 \mathrm{pg} / \mathrm{ml}$ and $<550 \mathrm{pg} / \mathrm{ml}$ for Perugia and Barcelona, respectively) [50, 51]. All individuals in the SAD and control groups had Mini-Mental State Examination (MMSE) scores available. Where possible participants in the SAD and control groups were matched in age and gender to participants with DS; age matching was not fully possible for the group with $\mathrm{SAD}$ due to the older age of this group (see Table 1).

For adults with SAD and controls, ethical approval was obtained from the regional ethics committee. Plasma and CSF samples were routinely collected in all subjects undergoing a diagnostic work-up for suspected neurodegenerative diseases, with informed written consent obtained for their use in research from patients or their representatives.

\section{APOE genotyping}

APOE genotype was determined using a Thermo Fisher Scientific TaqMan assay for SNPs rs7412 and rs429358 (Waltham, MA, USA).

\section{Sample processing and assays}

Blood samples from individuals with DS were collected in EDTA tubes after participants had undergone a cognitive assessment [47] and processed as quickly as feasible (within approximately $3 \mathrm{~h}$ ). Plasma was prepared by centrifuging samples for $10 \mathrm{~min}$ at $2200 \mathrm{~g}$, then the supernatant was aliquoted and stored at $-80^{\circ} \mathrm{C}$. Samples were only thawed immediately prior to analysis. Due to difficulties in obtaining blood samples from this population, we had to be pragmatic about the practicalities of collecting these samples. Blood samples were collected at a range of times throughout the day, with samples collected between $9.30 \mathrm{am}$ and $5.40 \mathrm{pm}$ and the majority of samples collected after midday (mean time of collection $=2.33 \mathrm{pm}$, standard deviation $=1.99 \mathrm{~h}$ ). It was not possible to take fasting blood samples for research purposes, though blood samples were typically taken at the end of a cognitive assessment that had lasted several hours, and participants did not eat during this time. In addition, the amount of time samples were in the freezer before analysis varied as it took a number of months to collect enough blood samples for our analysis. During this time, samples remained frozen at $-80^{\circ} \mathrm{C}$. To assess potential relationships between the number of months samples were frozen before analysis and the concentrations of each molecule, we performed correlational analyses; there were no significant relationships observed (results not shown).

Blood sample collection and processing methods for adults in the SAD and control groups from the EMIF cohort have been previously described [48].

For all three groups, plasma concentrations of $A \beta_{40}$, $\mathrm{A} \beta_{42}$, and $\mathrm{t}$-tau (Human Neurology 3-Plex $\mathrm{A}$ assay (N3PA)), IL1 $\beta$ (Human IL-1 $\beta$ 2.0), and IL10, IL6, and 
Table 1 Group demographics

\begin{tabular}{|c|c|c|c|c|}
\hline & DS & SAD & Controls & Group comparison \\
\hline$n$ & 31 & 27 & 27 & $\mathrm{~N} / \mathrm{A}$ \\
\hline Age (years) & $46.77 \pm 10.99(23-67)$ & $59.33 \pm 4.04(51-67)$ & $49.26 \pm 10.40(24-64)$ & $F(2,82)=14.84, p<0.001^{a}$ \\
\hline Sex & $\begin{array}{l}9(29.0 \%) \text { females, } 22 \text { (71.0\%) } \\
\text { males }\end{array}$ & $\begin{array}{l}9(33.3 \%) \text { females, } 18(66.7 \%) \\
\text { males }\end{array}$ & $\begin{array}{l}11(40.7 \%) \text { females, } 16 \text { (59.3\%) } \\
\text { males }\end{array}$ & $X(2)=0.89, p=0.641$ \\
\hline Intellectual disability severity ${ }^{\mathrm{b}}$ & $\begin{array}{l}17(54.8 \%) \text { mild, } 11(35.5 \%) \\
\text { moderate, } 3(9.7 \%) \text { severe }\end{array}$ & N/A & N/A & N/A \\
\hline APOE \&4 carrier & $\begin{array}{l}8(25.8 \%) \text { carriers, } 23(74.2 \%) \\
\text { non-carriers }\end{array}$ & $\begin{array}{l}10(37.0 \%) \text { carriers, } 17 \text { (63.0\%) } \\
\text { non-carriers }\end{array}$ & $\begin{array}{l}5(18.5 \%) \text { carriers, } 22(81.5 \%) \\
\text { non-carriers }\end{array}$ & $X(2)=2.38, p=0.304$ \\
\hline $\begin{array}{l}\text { Mini-Mental State } \\
\text { Examination (MMSE) score }\end{array}$ & N/A & $19.19 \pm 4.42(7-26)$ & $28.89 \pm 1.12(27-30)$ & $t(52)=-11.06, p<0.001^{c}$ \\
\hline
\end{tabular}

Values for age and MMSE score given as mean \pm standard deviation (range)

a $\mathrm{s}$ AD group older than DS and control groups (both $p<0.001$ ), no difference between DS and control groups $(p=0.915)$

${ }^{\mathrm{b}}$ Pre-dementia level, assessed via informant report based on everyday functional descriptions

csAD compared to controls only

TNFa (Human Cytokine 3-Plex A) were measured in duplicate using ultrasensitive Simoa immunoassays (Quanterix, Lexington, MA, USA) according to the manufacturer's instructions at the Institute of Psychiatry, Psychology and Neuroscience, King's College London. Samples from the three groups were blinded and randomised across two analytical plates for each assay. All duplicate measures for all targets had an average coefficient of variation (CV) of between 4 and $8 \%$.

For the group with DS, concentrations of NfL were previously obtained from samples taken at the same time [16]. Blood samples collected in lithium heparin tubes were first layered over a similar amount of Ficoll (GE Healthcare, Little Chalfont, UK), centrifuged for $40 \mathrm{~min}$ at $400 \mathrm{~g}$, then the supernatant was aliquoted and stored at $-80^{\circ} \mathrm{C}$ until analysis. Plasma NfL concentration was measured using the Simoa immunoassay (Human NF-light) (Quanterix, Lexington, MA, USA) according to the manufacturer's instructions at the Institute of Neurology, University College London. Values used in the present study had a median value of $27.09 \mathrm{pg} / \mathrm{ml}$ (range 10.97-112.60, $n=26$ ).

\section{Statistical analysis}

SPSS version 22 was used for analyses. Age and demographic factors were compared between groups using ANOVAs, two-sample $t$ tests, or chi-squared tests as appropriate. To compare concentrations of molecules between groups of adults with $\mathrm{DS}, \mathrm{sAD}$, and controls, we performed ANCOVAs for log-transformed concentrations (due to concentrations not being normally distributed) with age, sex, and the presence of an $A P O E$ \&4 allele included as covariates to adjust for their potentially confounding effects, with $\eta^{2}$ values determining the overall effect size of group and post hoc pairwise comparisons with Bonferroni corrections applied where appropriate. Due to concentrations not being normally distributed, non-parametric Spearman's rank correlational analysis was performed for each group separately to determine associations between concentrations of molecules and with age, in addition to associations with NfL concentration for the group with DS. Due to the number of correlations performed, correlation coefficients were used to determine relationships rather than $p$ values, with only strong and moderate correlations considered; these were defined as absolute values of correlation coefficients of 0.70 and above, and between 0.50 and 0.69 , respectively.

\section{Results}

Demographic information for individuals in the three groups can be seen in Table 1, with median values and ranges for molecule concentrations in Table 2 and Fig. 1. As expected, the group with sAD was significantly older than the group with DS and the control group. One plate for IL1 $\beta$ failed (containing 14 DS, 11 sAD, and 13 control samples), resulting in fewer samples measured for IL1 $\beta$. Demographic information and median values and ranges for molecule concentrations for adults with DS split into subgroups with and without clinical dementia can be found in Table 3 and Fig. 2. Statistical analysis was not performed to compare these subgroups due to small sample sizes.

Concentrations of $A \beta_{40}, A \beta_{42}$, and IL1 $\beta$ were higher for individuals with DS compared to both those with sAD and controls, with median concentrations of $A \beta_{40}$ and $A \beta_{42}$ increased approximately two-fold and median concentration of IL1 $\beta$ increased over ten-fold in the group with DS. The $A \beta_{42} / A \beta_{40}$ ratio was higher for controls compared to both individuals with DS and those with sAD (Table 2).

All three groups showed strong positive associations between $A \beta_{40}$ and $A \beta_{42}$ concentrations (see Table 4). Both the groups with DS and with SAD showed a moderate positive association between IL10 and TNF $\alpha$ concentrations. In addition, the control group showed a moderate negative association between the $A \beta_{42} / A \beta_{40}$ 
Table 2 Concentrations of biomarkers for each group and group comparisons

\begin{tabular}{|c|c|c|c|c|c|}
\hline & DS & $S A D$ & Controls & ANCOVA & Post hoc \\
\hline$\overline{A \beta_{40}}$ & $312.00(150.24-555.00)$ & $160.80(43.60-420.00)$ & $144.40(26.88-355.60)$ & $F(2,79)=24.28, p<0.001, \eta^{2}=0.38$ & $\begin{array}{l}\text { DS vs SAD } p<0.001 \\
\text { DS vs controls } p<0.001 \\
\text { SAD vs controls } p=0.506\end{array}$ \\
\hline$A \beta_{42}$ & $24.48(14.92-50.40)$ & $13.32(4.28-18.84)$ & $14.76(2.00-45.62)$ & $F(2,79)=20.36, p<0.001, \eta^{2}=0.34$ & $\begin{array}{l}\text { DS vs SAD } p<0.001 \\
\text { DS vs controls } p<0.001 \\
\text { SAD vs controls } p=0.710\end{array}$ \\
\hline$A \beta_{42} / A \beta_{40}$ & $0.09(0.05-0.13)$ & $0.08(0.04-0.11)$ & $0.10(0.07-0.17)$ & $F(2,79)=15.43, p<0.001, \eta^{2}=0.28$ & $\begin{array}{l}\text { DS vs SAD } p=1.000 \\
\text { DS vs controls } p<0.001 \\
\text { SAD vs controls } p<0.001\end{array}$ \\
\hline $\mathrm{A} \beta_{42} / \mathrm{t}$-tau & $20.60(1.17-93.33)$ & $10.23(0.77-52.00)$ & $10.59(1.14-82.25)$ & $F(2,79)=2.30, p=0.107, \eta^{2}=0.06$ & N/A \\
\hline T-tau & $1.45(0.18-12.72)$ & $1.00(0.33-24.48)$ & $1.49(0.16-10.24)$ & $F(2,79)=0.64, p=0.529, \eta^{2}=0.02$ & N/A \\
\hline $\operatorname{IL} 1 \beta^{\mathrm{a}}$ & $2.35(0.27-47.20)$ & $0.18(0.02-5.45)$ & $0.09(0.00-1.25)$ & $F(2,41)=13.84, p<0.001, \eta^{2}=0.40$ & $\begin{array}{l}\text { DS vs } S A D p=0.002 \\
\text { DS vs controls } p<0.001 \\
\text { SAD vs controls } p=1.000\end{array}$ \\
\hline $\mathrm{IL} 10^{\mathrm{b}}$ & $1.34(0.36-93.20)$ & $0.75(0.27-8.76)$ & $0.87(0.27-4.48)$ & $F(2,76)=2.38, p=0.100, \eta^{2}=0.06$ & N/A \\
\hline $1 \mathrm{~L} 6^{\mathrm{b}}$ & $2.12(0.36-1024.00)$ & $1.45(0.50-9.56)$ & $1.54(0.07-8.70)$ & $F(2,76)=2.54, p=0.086, \eta^{2}=0.06$ & N/A \\
\hline TNFa ${ }^{b}$ & $2.76(1.25-328.80)$ & $2.37(1.36-20.44)$ & $1.97(0.56-10.50)$ & $F(2,76)=2.42, p=0.096, \eta^{2}=0.06$ & N/A \\
\hline
\end{tabular}

Concentrations ( $\mathrm{pg} / \mathrm{ml}$ ) given are median (range). ANCOVA performed on log-transformed values and including age, sex, and the presence of an APOE $\varepsilon 4$ allele as covariates

${ }^{a}$ One plate failed (14 DS, 11 SAD, 13 controls)

${ }^{\mathrm{b}}$ Three samples failed (2 DS and 1 sAD)

ratio and IL10 concentration. Adults with DS showed several additional associations between concentrations of molecules (Table 4 and Fig. 3). Firstly, within this group, there was a moderate positive association between $A \beta_{42}$ and t-tau concentrations. Secondly, within the cytokines investigated, there was a strong positive association between IL1 $\beta$ and IL10, and a moderate positive association between IL6 and TNF $\alpha$. Finally, IL1 $\beta$ concentration showed a moderate positive association with t-tau concentration and a moderate negative association with the $\mathrm{A} \beta_{42} / \mathrm{t}$-tau ratio. In addition, in the group with DS, only NfL concentration showed a moderate positive association with age, as previously published [16]. There were no other moderate or strong associations for molecular concentrations or with age across any group.

\section{Discussion}

We used ultrasensitive assays to compare plasma concentrations of $A \beta$ peptides, tau, and selected cytokines between adults with DS, adults with SAD, and controls who were age-matched to the group with DS. We found significantly higher concentrations of $A \beta_{40}, A \beta_{42}$, and IL1 $\beta$ in those with DS compared to those with SAD and controls. The $A \beta_{42} / A \beta_{40}$ ratio was higher in controls compared to those with DS or SAD, indicating higher plasma concentrations of $A \beta_{42}$ relative to concentrations of $A \beta_{40}$ in controls. These group differences were observed when we accounted for age, sex, and the presence of an $A P O E$ \&4 allele.

Several positive associations were found between concentrations of different cytokines, in particular for the group with DS, possibly reflecting a more activated immune system in DS which may be associated with higher rates of infection and/or autoimmune disorders [39, 40]. The group with DS also showed positive associations between concentrations of $\mathrm{t}$-tau and both $\mathrm{A} \beta_{42}$ and IL1 $\beta$, and a negative association between IL1 $\beta$ and the $A \beta_{42} /$ $\mathrm{t}$-tau ratio, while the control group showed a negative association between concentration of IL10 and the A $\beta_{42} /$ $\mathrm{A} \beta_{40}$ ratio.

Results relating to concentrations of $A \beta$ peptides and their ratio indicate both likely differences and similarities in the development of AD between those with DS and those with SAD. Similar to the results of previous studies, we observed higher concentrations of $A \beta_{40}$ and $A \beta_{42}$ in those with DS compared to those with SAD and controls [17, 27-37]. This observation is likely due to triplication of the APP gene in adults with DS leading to elevated production of $A \beta$ peptides. Concentrations of $A \beta_{40}$ and $A \beta_{42}$ in adults with DS were approximately double those in the other groups, rather than 1.5 times higher as may be expected based on the presence of an additional $A P P$ gene alone, suggesting that factor(s) other than $A P P$ triplication may contribute to increased $A \beta$ concentrations [52], such as a positive feedback loop or an overloaded perivascular drainage system. Although concentrations of $A \beta_{40}$ and $A \beta_{42}$ were higher in those with DS compared to those with SAD, there was no difference in the $A \beta_{42} / A \beta_{40}$ ratio between these two groups. This may suggest the relative processing and deposition of $A \beta_{40}$ and $A \beta_{42}$ in the brain is similar between the two groups. The higher concentrations of $A \beta_{40}$ and 

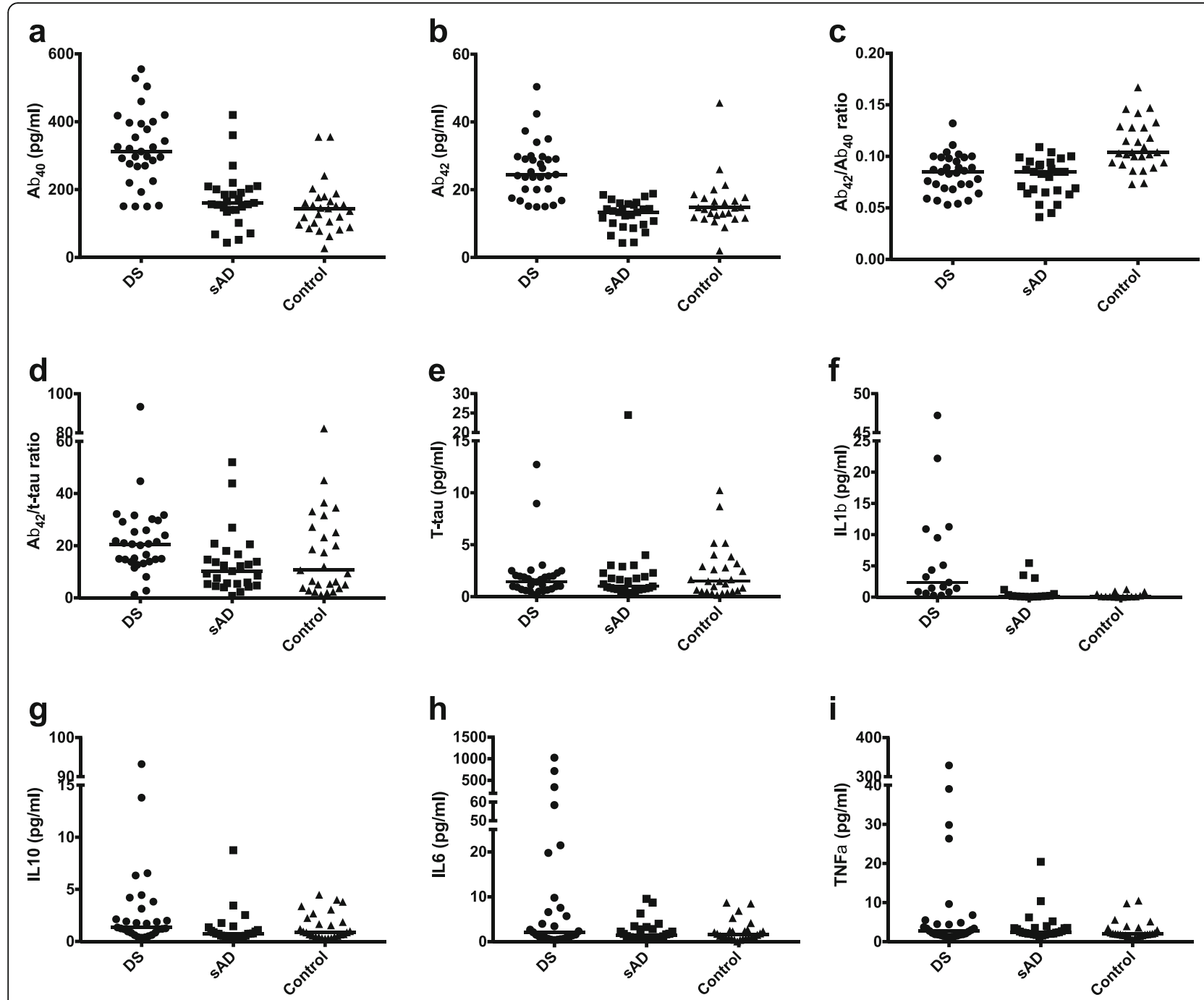

Fig. 1 Concentrations of biomarkers for each group. a $A \beta_{40}, \mathbf{b} A \beta_{42}, \mathbf{c} A \beta_{42} / A \beta_{40}, \mathbf{d} A \beta_{42} / \mathrm{t}$-tau, e t-tau, $\mathbf{f}\|L 1 \beta, \mathbf{g}\| L 10$, $\mathbf{h} \| L 6$, and $\mathbf{i} T N F a$. Lines indicate median value $(\mathrm{pg} / \mathrm{ml})$

$\mathrm{A} \beta_{42}$ in adults with DS as compared to those with sAD, and no difference in the $A \beta_{42} / A \beta_{40}$ ratio between the two groups, is despite the younger age of the group with DS compared to those with sAD. In contrast, the $A \beta_{42} /$ $\mathrm{A} \beta_{40}$ ratio was higher in controls, indicating this group has a higher relative plasma $A \beta_{42}$ concentration and/ or a lower relative plasma $A \beta_{40}$ concentration compared to the other two groups. This may be due to the build-up of $A \beta$ plaques in the brains of those with DS and those with sAD, with $A \beta_{42}$ a main component, resulting in a relative decrease of free $A \beta_{42}$ and a lower $A \beta_{42} / A \beta_{40}$ ratio. Similarly, previous studies have associated a lower $A \beta_{42} / A \beta_{40}$ ratio with a higher risk of developing dementia [53] and with increased $A \beta$ accumulation in the brain as measured using $A \beta$ positron emission tomography [54-57].
Adults with DS also showed significantly higher concentrations of IL1 $\beta$ compared to adults with SAD and controls [46], and in the group with DS, IL1 $\beta$ concentration was positively correlated with t-tau concentration and negatively correlated with the $A \beta_{42} / t$-tau ratio. Given the lack of an association between concentrations of IL1 $\beta$ and $A \beta_{42}$ in this group, it is likely the latter association is driven by the association with t-tau. IL $1 \beta$ is a pro-inflammatory cytokine produced by activated macrophages, and previous studies have indicated increased concentrations of IL1 $\beta$ are associated with AD [20] and precede cognitive decline [19]. The increase in IL1 $\beta$ concentration in DS may reflect increased vulnerability to peripheral infections [39] and/or increased prevalence of autoimmune disorders in those with DS [40]. Plasma t-tau concentration is associated 
Table 3 Demographic information and concentrations of biomarkers for adults with DS with and without clinical dementia

\begin{tabular}{|c|c|c|}
\hline & Dementia & No dementia \\
\hline$n$ & 7 & 24 \\
\hline Age (years) & $52.00 \pm 10.36(40-67)$ & $45.25 \pm 10.90(23-65)$ \\
\hline Sex & 2 (28.6\%) females, 5 (71.4\%) males & $7(29.2 \%)$ females, 17 (70.8\%) males \\
\hline Intellectual disability severity ${ }^{a}$ & 5 (71.4\%) mild, 1 (14.3\%) moderate, 1 (14.3\%) severe & $12(50.0 \%)$ mild, 10 (41.7\%) moderate, 2 (8.3\%) severe \\
\hline$A P O E$ \&4 carrier & $4(57.1 \%)$ carriers, 3 (42.9\%) non-carriers & $4(16.7 \%)$ carriers, $20(83.3 \%)$ non-carriers \\
\hline$A \beta_{40}$ & $320.80(268.20-555.00)$ & $304.80(150.24-528.00)$ \\
\hline$A \beta_{42}$ & $26.36(15.16-42.40)$ & $24.14(14.92-50.40)$ \\
\hline$A \beta_{42} / A \beta_{40}$ & $0.08(0.05-0.09)$ & $0.09(0.05-0.13)$ \\
\hline $\mathrm{A} \beta_{42} / \mathrm{t}$-tau & $14.76(2.73-29.18)$ & $20.86(1.17-93.33)$ \\
\hline T-tau & $1.88(0.99-8.96)$ & $1.27(0.18-12.72)$ \\
\hline $\mathrm{IL} 1 \beta^{\mathrm{b}}$ & $3.79(1.65-5.10)$ & $1.44(0.27-47.20)$ \\
\hline $\operatorname{IL} 10^{\mathrm{C}}$ & $1.78(0.62-6.33)$ & $1.26(0.36-93.20)$ \\
\hline IL6 & $2.12(0.44-58.40)$ & $2.12(0.36-1024.00)$ \\
\hline $\mathrm{TNFa}^{\mathrm{c}}$ & $2.58(1.25-29.84)$ & $3.08(1.30-328.80)$ \\
\hline $\mathrm{NfL}^{d}$ & $59.84(16.36-112.60)$ & $25.10(10.97-55.45)$ \\
\hline
\end{tabular}

Values for age given as mean \pm standard deviation (range), and concentrations $(\mathrm{pg} / \mathrm{ml})$ given are median (range)

aPre-dementia level, assessed via informant report based on everyday functional descriptions

${ }^{\mathrm{b}}$ One plate failed (3 with dementia, 11 without dementia)

'Two samples failed (both without dementia)

${ }^{\mathrm{d}}$ Five samples missing (1 with dementia, 4 without dementia)

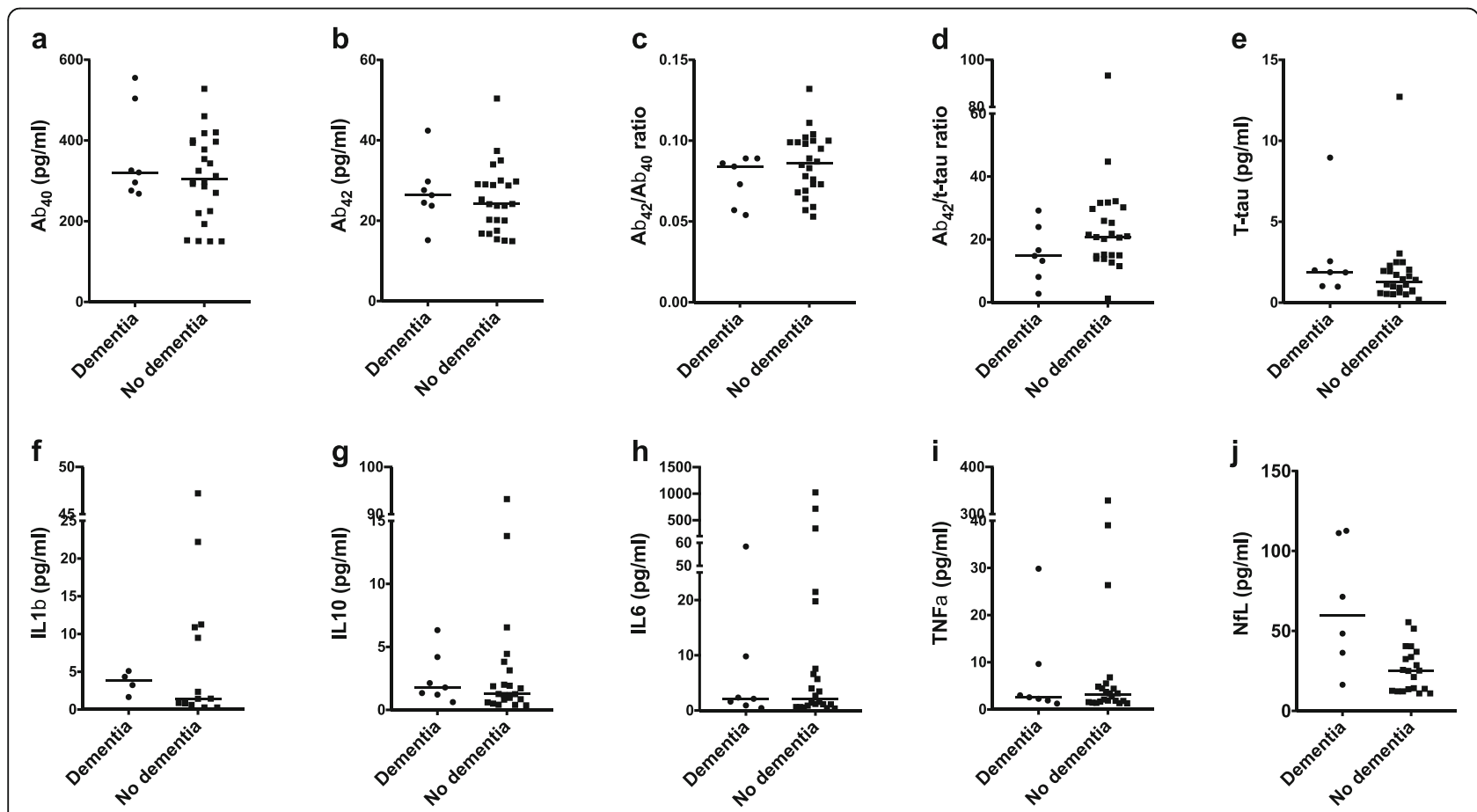

Fig. 2 Concentrations of biomarkers for adults with DS with and without clinical dementia. a $A \beta_{40}, \mathbf{b} A \beta_{42}, \mathbf{c} A \beta_{42} / A \beta_{40}, \mathbf{d} A \beta_{42} / \mathrm{t}-\mathrm{tau}$, e t-tau, $\mathbf{f}$ IL1 $\beta, \mathbf{g}\|\mathrm{L} 10, \mathbf{h}\| \mathrm{L}, \mathbf{i} \mathrm{TNFa}$, and $\mathbf{j} \mathrm{NfL}$. Lines indicate median value $(\mathrm{pg} / \mathrm{ml})$ 
Table 4 Relationships between concentrations of biomarkers for each group

\begin{tabular}{|c|c|c|c|c|c|c|c|c|c|c|}
\hline & $A \beta_{42}$ & $\mathbf{A} \beta_{42} / \mathbf{A} \beta_{40}$ & $\mathbf{A} \beta_{42} / \mathrm{t}$-tau & T-tau & IL1 $\beta$ & IL10 & IL6 & TNFa & $\mathrm{NfL}$ & Age \\
\hline $\mathbf{A} \boldsymbol{\beta}_{40}$ & $0.731(<0.001)$ & $-0.554(0.001)$ & \begin{tabular}{|l}
$0.012(0.950)$ \\
\end{tabular} & \begin{tabular}{|l|l|}
$0.271(0.140)$ \\
\end{tabular} & \begin{tabular}{|l}
$0.208(0.422)$ \\
\end{tabular} & \begin{tabular}{|l|l|}
$0.115(0.554)$ \\
\end{tabular} & \begin{tabular}{|l|}
$0.019(0.922)$ \\
\end{tabular} & \begin{tabular}{|l|}
$0.260(0.173)$ \\
\end{tabular} & $0.360(0.071)$ & $0.236(0.200)$ \\
\hline$A \beta_{42}$ & - & $0.051(0.786)$ & 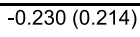 & \begin{tabular}{|l|}
$0.558(0.001)$ \\
\end{tabular} & $0.105(0.687)$ & \begin{tabular}{|l|}
$0.139(0.471)$ \\
\end{tabular} & $-0.220(0.251)$ & \begin{tabular}{|l|}
$0.028(0.884)$ \\
\end{tabular} & $0.251(0.216)$ & \begin{tabular}{|l}
$0.072(0.702)$ \\
\end{tabular} \\
\hline $\mathbf{A} \beta_{42} / \mathbf{A} \beta_{40}$ & - & - & $-0.229(0.215)$ & $0.227(0.219)$ & $-0.245(0.343)$ & \begin{tabular}{|l}
$-0.134(0.488)$ \\
\end{tabular} & $-0.285(0.134)$ & $-0.465(0.011)$ & $-0.294(0.145)$ & $-0.161(0.386)$ \\
\hline$A \beta_{42} /$ t-tau & - & - & - & $-0.884(<0.001)$ & $-0.588(0.013)$ & \begin{tabular}{|l}
$-0.112(0.563)$ \\
\end{tabular} & \begin{tabular}{|l|}
$0.244(0.202)$ \\
\end{tabular} & \begin{tabular}{|l|}
$0.204(0.289)$ \\
\end{tabular} & $-0.151(0.460)$ & $-0.154(0.409)$ \\
\hline T-tau & - & - & - & - & $0.526(0.030)$ & \begin{tabular}{|l|}
$0.150(0.437)$ \\
\end{tabular} & \begin{tabular}{|l}
$-0.297(0.118)$ \\
\end{tabular} & \begin{tabular}{|l|}
$-0.224(0.242)$ \\
\end{tabular} & $0.172(0.401)$ & \begin{tabular}{|l|l|}
$0.128(0.491)$ \\
\end{tabular} \\
\hline IL1 $\beta$ & - & - & - & - & - & \begin{tabular}{|l|}
$0.723(0.001)$ \\
\end{tabular} & \begin{tabular}{|l|l|}
$0.219(0.397)$ \\
\end{tabular} & \begin{tabular}{|l|}
$0.324(0.205)$ \\
\end{tabular} & $-0.055(0.859)$ & $0.168(0.519)$ \\
\hline IL10 & - & - & - & - & - & - & \begin{tabular}{|l|}
$0.383(0.040)$ \\
\end{tabular} & \begin{tabular}{|l|}
$0.531(0.003)$ \\
\end{tabular} & $-0.117(0.585)$ & $-0.061(0.753)$ \\
\hline IL6 & - & - & - & - & - & - & - & \begin{tabular}{|l|}
$0.506(0.005)$ \\
\end{tabular} & $0.110(0.610)$ & $-0.039(0.841)$ \\
\hline TNF $\alpha$ & - & - & - & - & - & - & - & - & $0.171(0.424)$ & \begin{tabular}{|l}
$0.038(0.845)$ \\
\end{tabular} \\
\hline $\mathrm{NfL}$ & - & - & 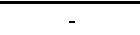 & - & - & - & - & 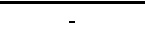 & - & $0.600(0.001)$ \\
\hline
\end{tabular}

a) Individuals with DS. Values given are Spearman's rank correlation coefficient $r_{s}(p$ value).

\begin{tabular}{|c|c|c|c|c|c|c|c|c|c|}
\hline & $A \beta_{42}$ & $\bar{A} \beta_{42} / \mathbf{A} \beta_{40}$ & $\mathbf{A} \beta_{42} / \mathrm{t}-\operatorname{tau}$ & T-tau & IL1 $\beta$ & IL10 & IL6 & TNF $\alpha$ & \\
\hline$A \beta_{40}$ & $0.736(<0.001)$ & $-0.522(0.005)$ & $0.433(0.024)$ & $-0.093(0.646)$ & $0.199(0.461)$ & $-0.304(0.131)$ & $-0.020(0.925)$ & $-0.289(0.152)$ & $-0.220(0.271)$ \\
\hline$A \beta_{42}$ & - & $0.051(0.801)$ & $0.324(0.099)$ & $0.103(0.610)$ & $-0.262(0.326)$ & $-0.157(0.443)$ & $-0.432(0.028)$ & $-0.290(0.150)$ & $-0.186(0.354)$ \\
\hline $\mathbf{A} \boldsymbol{\beta}_{42} / \mathbf{A} \beta_{40}$ & - & - & $-0.409(0.034)$ & $0.356(0.068)$ & $-0.499(0.049)$ & $0.155(0.450)$ & $-0.379(0.056)$ & $0.153(0.457)$ & $-0.022(0.913)$ \\
\hline$A \beta_{42} /$ t-tau & - & - & - & $-0.831(<0.001)$ & $0.449(0.081)$ & $-0.410(0.038)$ & $-0.054(0.793)$ & $-0.429(0.029)$ & $0.034(0.865)$ \\
\hline T-tau & - & - & - & - & $-0.391(0.135)$ & $0.295(0.144)$ & $-0.097(0.637)$ & $0.295(0.144)$ & $-0.116(0.566)$ \\
\hline IL1 $\beta$ & - & - & - & - & - & $-0.081(0.766)$ & $0.429(0.098)$ & $0.289(0.277)$ & $0.146(0.589)$ \\
\hline IL10 & - & - & - & - & - & - & $-0.036(0.862)$ & $0.645(<0.001)$ & $0.109(0.597)$ \\
\hline IL6 & - & - & - & - & - & - & - & $0.205(0.314)$ & $-0.132(0.521)$ \\
\hline TNFa & - & - & - & - & - & - & - & & $-0.115(0.575)$ \\
\hline
\end{tabular}

b) Individuals with sAD. Values given are Spearman's rank correlation coefficient $r_{s}$ ( $p$ value).

\begin{tabular}{|c|c|c|c|c|c|c|c|c|c|}
\hline & $A \beta_{42}$ & $\mathbf{A} \beta_{42} / \mathbf{A} \beta_{40}$ & $A \beta_{42} / \mathrm{t}$-tau & T-tau & IL1 $\beta$ & IL10 & IL6 & TNF $\alpha$ & Age \\
\hline$A \beta_{40}$ & $0.921(<0.001)$ & $-0.574(0.002)$ & $0.213(0.286)$ & $0.068(0.735)$ & $-0.135(0.646)$ & $0.426(0.027)$ & $-0.259(0.193)$ & $0.217(0.276)$ & $-0.176(0.381)$ \\
\hline$A \beta_{42}$ & - & $-0.330(0.092)$ & $0.330(0.092)$ & $-0.023(0.909)$ & $-0.188(0.521)$ & $0.341(0.082)$ & $-0.263(0.186)$ & $0.099(0.622)$ & $-0.210(0.293)$ \\
\hline $\mathbf{A} \boldsymbol{\beta}_{42} / \mathbf{A} \beta_{40}$ & - & - & $0.072(0.721)$ & $-0.004(0.986)$ & $-0.236(0.416)$ & $-0.536(0.004)$ & $0.247(0.214)$ & $-0.352(0.072)$ & $0.056(0.783)$ \\
\hline $\mathbf{A} \beta_{42} / t-\operatorname{tau}$ & - & - & - & $-0.899(<0.001)$ & $-0.152(0.603)$ & $0.090(0.655)$ & $0.259(0.192)$ & $-0.070(0.730)$ & $-0.050(0.803)$ \\
\hline T-tau & - & - & - & - & $-0.002(0.994)$ & $-0.120(0.550)$ & $-0.275(0.165)$ & $0.039(0.845)$ & $-0.008(0.967)$ \\
\hline IL1 $\beta$ & - & - & - & - & - & $-0.082(0.781)$ & $-0.360(0.206)$ & $-0.404(0.151)$ & $-0.047(0.874)$ \\
\hline IL10 & - & - & - & - & - & - & $0.052(0.797)$ & $0.387(0.046)$ & $-0.043(0.833)$ \\
\hline IL6 & - & - & - & - & - & - & - & $0.282(0.154)$ & $-0.030(0.882)$ \\
\hline TNFa & - & - & - & - & - & - & - & - & $0.054(0.790)$ \\
\hline
\end{tabular}

c) Controls. Values given are Spearman's rank correlation coefficient $r_{s}(p$ value).

\section{$<-0.7<-0.5<-0.3 \quad>0.3 \quad>0.5 \quad>0.7$}

d) Colour key, with colours indicating the strength of relationships as determined using correlation coefficients

with severity of neurodegeneration, thought to be due to neuronal damage causing tau release from the brain [58]. The association between IL1 $\beta$ and plasma $\mathrm{t}$-tau in DS may therefore indicate that raised levels of pro-inflammatory cytokines may contribute to neurodegeneration in this group, or increased concentration of pro-inflammatory cytokines may be a protective response to neuronal damage. Raised IL1 $\beta$ concentration in adults with DS may also have implications for the development of microbleeds or strokes in response to cerebral amyloid angiopathy, as discussed in Buss et al. [59].
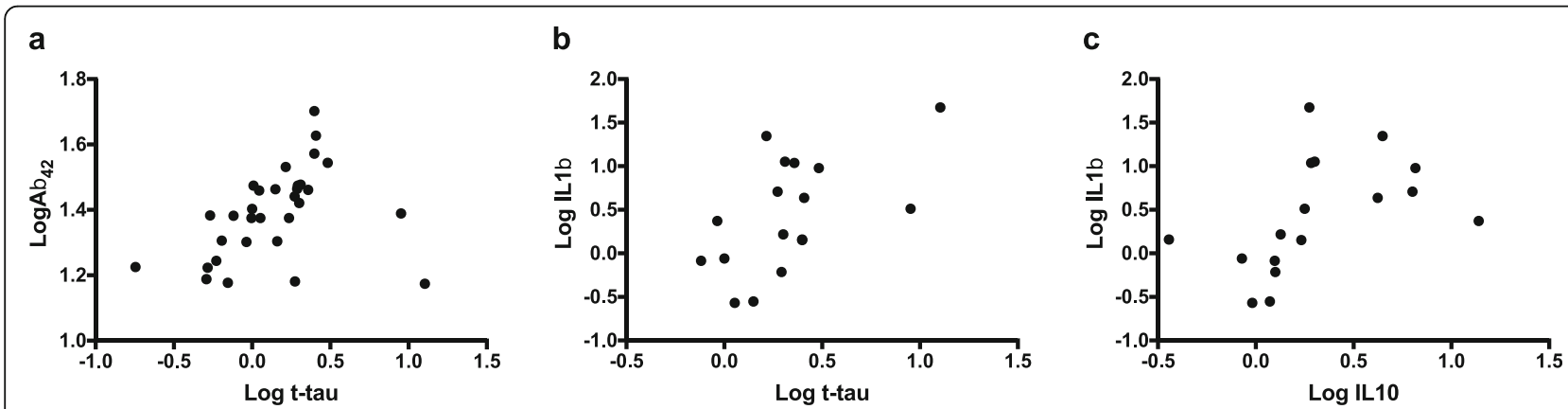

Fig. 3 Relationships between biomarkers for adults with DS. a Log A $\beta_{42}$ and $\log t$-tau, $\mathbf{b} \log$ t-tau and $\log I L 1 \beta$, and $\mathbf{c} \log I L 1 \beta$ and $\log I L 10$ 
We did not find any associations with age and concentrations of $\mathrm{A} \beta$ peptides, tau, or cytokines in any group. Previous studies have reported contrasting results regarding the association between $A \beta_{42}$ and age in DS, with some studies also finding no association [29, 32, 33, 6062], some finding a positive association [34, 63, 64], and some finding a negative association [27, 30]. Previous studies have also suggested age shows a positive correlation with concentrations of $\mathrm{A} \beta_{40}[33,34]$ and $t$-tau [38] in DS. It has further been suggested $A \beta_{42}$ and $A \beta_{40}$ concentrations may not show a linear relationship with age in DS, being stable until age 50 and then decreasing [65]. As reported previously, we found a positive association between age and NfL concentration in adults with DS [16]. Due to the strong association between age and the development of dementia in adults with DS, this may indicate NfL is a more suitable biomarker for dementia progression than $A \beta$ or tau in this group. Further supporting the use of NfL as a potential biomarker for dementia progression in DS, our group and others have previously shown that NfL concentration is significantly higher in adults with DS and dementia compared to those with DS without dementia $[16,17]$.

Identifying a biomarker for dementia in DS is important for early detection and for monitoring disease progression and is required for clinical intervention studies in combination with cognitive tests sensitive to detecting cognitive decline [66]. In addition to NfL, several other potential plasma or urinary biomarkers have been proposed, including neopterin (a marker for activated cellular immunity and inflammation) [67, 68], 3-methoxy-4-hydroxyphenylglycol (MHPG, a noradrenergic metabolite) [69], dehydroepiandrosterone (DHEA, a steroid hormone) [70], or molecules associated with oxidative stress, specifically superoxide dismutase enzymes (SOD) [71] and iPF2alpha [72]. It has also been suggested that a combination of baseline concentrations and changes in $A \beta$ peptides and inflammatory molecules may be predictive of cognitive decline in adults with DS [31]. Further longitudinal studies assessing multiple potential biomarkers with large samples and multiple time points starting prior to the onset of any cognitive decline are needed to clarify the ideal biomarker for dementia in DS. Blood samples are less invasive, easier, quicker, and cheaper to obtain than CSF samples, with additional practical considerations in those with DS often limiting the feasibility of obtaining CSF. The identification of a plasma biomarker for dementia progression in DS is therefore essential. Such a biomarker will be of particular use in the population with DS due to the pre-morbid variability in intellectual disability severity posing an additional challenge for the clinical diagnosis of dementia.

However, aside from plasma $A \beta_{42}$ (and the $A \beta_{42} / A \beta_{40}$ ratio), where a reasonably robust association with cerebral $\beta$-amyloidosis has emerged [73], it is unknown how well plasma concentrations of molecules reflect changes within the brain, and the relative contribution of different sources (including the brain and platelets) to plasma concentrations is unknown. To better understand concentrations of $A \beta_{42}$ and tau in the brain of adults with DS using blood samples, Hamlett et al. [74] measured concentrations from neuronal exosomes within the blood, finding higher concentrations of $A \beta_{42}$ and phosphorylated tau in DS compared to controls. These results indicate an alternative to measuring plasma concentrations. Future studies are needed to further explore the relationships between plasma concentrations of molecules and changes within the brain.

Studies assessing blood biomarkers in DS typically consist of relatively small sample sizes [31, 38], in large part due to difficulties in obtaining blood samples from these individuals. Although our sample size is large enough to demonstrate group differences in plasma concentrations of some molecules, it is possible a larger sample would reveal additional group differences. It should also be noted we included individuals with varying stages of dementia progression in the group with DS, which may have contributed to the presence of some relationships in this group and not in the other groups, such as the positive associations between concentrations of $t$-tau and both $A \beta_{42}$ and IL1 $\beta$. Despite this, all adults with DS are thought to have $A \beta$ neuropathology by their mid-30s $[1,7]$, and so the group with DS is likely similar in terms of the presence of $\mathrm{A} \beta$ neuropathology. $\mathrm{Al}-$ though some studies have suggested stage of dementia progression in DS may be associated with varying concentrations of $A \beta_{40}$ and $A \beta_{42}[28,31,32,63,75]$, other studies have reported no differences in $A \beta_{40}$ or $A \beta_{42}$ concentrations in those with DS with and without dementia [29, 31, 60-62, 76]. A recent study has further suggested that plasma $A \beta_{40}$ and $A \beta_{42}$ concentrations show poor diagnostic performance for dementia in DS [17]. Given these differences in results, which may be due to differences in study populations (including differences in age, dementia stage, or dementia duration) and assay sensitivity or sampling procedures, further larger, longitudinal studies with multiple time points starting prior to the onset of any cognitive decline and using ultrasensitive assays such as those used in the present study are needed to clarify whether changes in $A \beta_{40}$ or $\mathrm{A} \beta_{42}$ concentrations are associated with the development and progression of dementia in DS.

Finally, considering the amyloid hypothesis of AD and associated changes in people with DS, our results support the triplication of APP leading to the overproduction of $A \beta$ peptides and resulting in elevated concentrations of $A \beta_{40}$ and $A \beta_{42}$ in people with DS compared to the sAD and control groups. Within the group with DS, the 
positive relationship between NfL concentration and age (and also the previously published association between higher NfL concentration and dementia development [16, 17]) indicates plasma NfL concentration reflects neuronal damage in the brain. We did not find group differences in concentrations of $\mathrm{t}$-tau or cytokines that may indicate altered concentrations with the development of dementia. It is possible our relatively small sample size limited our power to detect these differences. Alternatively, it is possible that the stage of dementia progression is relevant to detect group differences, and changes may occur in the earlier prodromal stage only. Again, larger, longitudinal studies with multiple time points starting prior to the onset of any cognitive decline would be required to determine associations between plasma molecular concentrations and the development of dementia.

\section{Conclusions}

We compared plasma concentrations of $A \beta$ peptides, tau, and selected cytokines between adults with DS, adults with SAD, and controls age-matched to the group with DS to investigate molecular mechanisms relevant to the development of AD in DS using ultrasensitive assays. Our results indicated the likely similar processing and deposition of $A \beta_{40}$ and $A \beta_{42}$ in those with DS and sAD, though those with DS showed much higher concentrations of these molecules, despite their younger age. In addition, IL1 $\beta$ concentration is far higher in those with DS compared to those with SAD and controls, and a positive association between IL1 $\beta$ and $t$-tau in those with DS may indicate IL1 $\beta$ is associated with neurodegeneration in this group. Our results also indicated that NfL concentration may be the most suitable biomarker for dementia progression in DS. Future longitudinal studies to identify biomarker changes over time associated with pathological and clinical progression are needed to confirm these findings.

\footnotetext{
Abbreviations

AD: Alzheimer's disease; APP: Amyloid precursor protein; A $\beta$ : Amyloid- $\beta$; CSF: Cerebrospinal fluid; CV: Coefficient of variation;

DHEA: Dehydroepiandrosterone; DS: Down syndrome; EMIF: European Medical Informatics Framework; IFN-ү: Interferon- $\gamma$; IL10: Interleukin 10; IL1 $\beta$ : Interleukin 13; IL6: Interleukin 6; MHPG: 3-Methoxy-4hydroxyphenylglycol; MMSE: Mini-Mental State Examination; N3PA: Neurology 3-Plex A assay; NfL: Neurofilament light; SAD: Sporadic Alzheimer's disease; SOD: Superoxide dismutase enzymes; TNFa: Tumour necrosis factor $a_{\text {; }}$ t-tau: Total tau
}

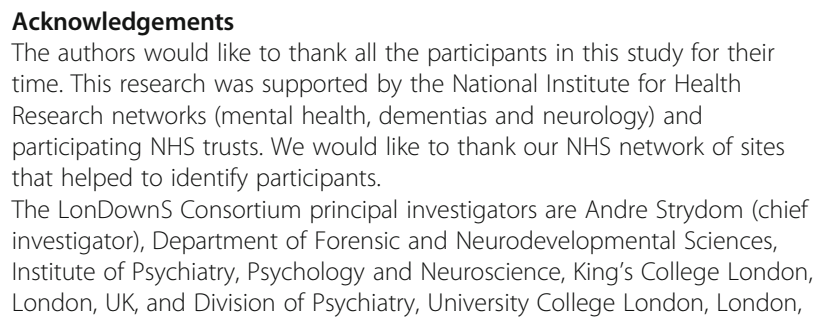

UK; Elizabeth Fisher, Department of Neurodegenerative Disease, Institute of Neurology, University College London, London, UK; Dean Nizetic, Blizard Institute, Barts and the London School of Medicine, Queen Mary University of London, London, UK, and Lee Kong Chian School of Medicine, Nanyang Technological University, Singapore, Singapore; John Hardy, Reta Lila Weston Institute, Institute of Neurology, University College London, London, UK, and UK Dementia Research Institute at UCL, London, UK; Victor Tybulewicz, Francis Crick Institute, London, UK, and Department of Medicine, Imperial College London, London, UK; and Annette Karmiloff-Smith, Birkbeck University of London, London, UK (deceased). We would like to thank Tamara Al-Janabi (Division of Psychiatry, University College London, London, UK) for managing the project as a whole. We would like to thank David Zhang for support with genetic analysis for samples from adults with DS (Institute of Neurology, University College London, London, UK).

\section{Funding}

This work was funded by a Wellcome Trust Strategic Award (grant number: 098330/Z/12/Z) conferred upon The London Down Syndrome (LonDownS) Consortium, and an award from the UCL ARUK network. Our work is further supported by the Baily Thomas Charitable Fund. $\mathrm{HZ}$ is a Wallenberg Academy Fellow and receives support from the European Research Council, the Swedish Research Council, and Frimurarestiftelsen. $\mathrm{HZ}$ is further supported by the Wolfson Foundation, the Wellcome Trust, and the UK Dementia Research Institute. The study funders and sponsors had no role in study design, data collection, data analysis, data interpretation, writing of the report, or the decision to submit for publication.

\section{Availability of data and materials}

The datasets used and/or analysed during the current study are available from the corresponding author on reasonable request.

\section{Authors' contributions}

CMS, FKW, and AS designed the study and data analysis. CMS, SH, and RH contributed significantly to the recruitment and data collection of adults with DS. AL, SL, and LP provided the samples for adults with SAD and controls. NJA and AH performed the biomarker measurements. KYM and JH contributed to the genetic analysis and interpretation of the genetic data for the samples from adults with DS. HZ contributed to the NfL analysis for the samples from adults with DS. CMS analysed the data and drafted the initial version of the report. All authors contributed to the revision and editing of the report. All authors read and approved the final manuscript.

\section{Ethics approval and consent to participate}

For adults with DS, ethical approval was obtained from the North West Wales Research Ethics Committee (13/WA/0194). Where individuals had capacity to consent for themselves we obtained written informed consent. Where individuals did not have capacity to consent a consultee was asked to approve the individual's inclusion based on their knowledge of the individual and his/ her wishes, in accordance with the UK Mental Capacity Act 2005.

For adults with SAD and controls, ethical approval was obtained from the regional ethics committee. Plasma and CSF samples were routinely collected in all subjects undergoing a diagnostic work-up for suspected neurodegenerative diseases, with informed written consent obtained for their use in research from patients or their representatives.

\section{Consent for publication}

Not applicable.

\section{Competing interests}

$\mathrm{HZ}$ has served at scientific advisory boards for Eli Lilly, Roche Diagnostics and Wave, has received travel support from Teva, and is a co-founder of Brain Biomarker Solutions in Gothenburg AB, a GU Ventures-based platform company at the University of Gothenburg. The other authors declare that they have no competing interests.

\section{Publisher's Note}

Springer Nature remains neutral with regard to jurisdictional claims in published maps and institutional affiliations. 


\section{Author details}

'Department of Forensic and Neurodevelopmental Sciences, Institute of Psychiatry, Psychology and Neuroscience, King's College London, 16 De Crespigny Park, London SE5 8AF, UK. ${ }^{2}$ Division of Psychiatry, University College London, London, UK. ${ }^{3}$ The LonDownS Consortium (London Down Syndrome Consortium), London, UK. ${ }^{4}$ Maurice Wohl Clinical Neuroscience, Institute of Psychiatry, Psychology and Neuroscience, King's College London, London, UK. ${ }^{5}$ NIHR Biomedical Research Centre for Mental Health, Biomedical Research Unit for Dementia at South London, and Maudsley NHS Foundation, London, UK. 'Department of Psychiatry and Neurochemistry, Institute of Neuroscience and Physiology, Sahlgrenska Academy at the University of Gothenburg, Mölndal, Sweden. ${ }^{2}$ Wallenberg Centre for Molecular \& Translational Medicine, University of Gothenburg, Gothenburg, Sweden. ${ }^{8}$ Department of Neurodegenerative Disease, Institute of Neurology, University College London, London, UK. ${ }^{9}$ Department of Molecular Neuroscience, Institute of Neurology, University College London, London, UK. ${ }^{10}$ Division of Life Science, Hong Kong University of Science and Technology, Hong Kong, SAR, People's Republic of China. " Reta Lila Weston Institute, Institute of Neurology, University College London, London, UK. ${ }^{12}$ Memory Unit, Neurology Department, Hospital de la Santa Creu i Sant Pau, Barcelona, Spain. ${ }^{13}$ Department of Psychiatry, University of Oxford, Oxford, UK. ${ }^{14}$ Centre for Memory Disturbances, Laboratory of Clinical Neurochemistry, Section of Neurology, Department of Medicine, University of Perugia, Perugia, Italy. ${ }^{15}$ Clinical Neurochemistry Laboratory, Sahlgrenska University Hospital, Mölndal, Sweden. ${ }^{16}$ UK Dementia Research Institute at UCL, London, UK.

Received: 28 August 2018 Accepted: 21 February 2019

Published online: 21 March 2019

\section{References}

1. Wiseman FK, Al-Janabi T, Hardy J, Karmiloff-Smith A, Nizetic D, Tybulewicz VL, Fisher EM, Strydom A. A genetic cause of Alzheimer disease: mechanistic insights from Down syndrome. Nat Rev Neurosci. 2015;16:564-74.

2. McCarron M, McCallion P, Reilly E, Mulryan N. A prospective 14-year longitudinal follow-up of dementia in persons with Down syndrome. J Intellect Disabil Res. 2014;58:61-70.

3. Sinai A, Mokrysz C, Bernal J, Bohnen I, Bonell S, Courtenay K, Dodd K, Gazizova $D$, Hassiotis $A$, Hillier $R$, et al. Predictors of age of diagnosis and survival of Alzheimer's disease in Down syndrome. J Alzheimers Dis. 2018;61:717-28.

4. Hithersay R, Startin CM, Hamburg S, Mok KY, Hardy J, Fisher EMC, Tybulewicz VLJ, Nizetic D, Strydom A. Association of dementia with mortality among adults with Down syndrome older than 35 years. JAMA Neurol. 2019;76:152-60.

5. Wu J, Morris JK. The population prevalence of Down's syndrome in England and Wales in 2011. Eur J Hum Genet. 2013;21:1016-9.

6. Mann DMA, Davidson YS, Robinson AC, Allen N, Hashimoto T, Richardson A, Jones M, Snowden JS, Pendleton N, Potier MC, et al. Patterns and severity of vascular amyloid in Alzheimer's disease associated with duplications and missense mutations in APP gene, Down syndrome and sporadic Alzheimer's disease. Acta Neuropathol. 2018:136:569-87.

7. Mann DM. Alzheimer's disease and Down's syndrome. Histopathology. 1988; 13:125-37.

8. Zis $\mathrm{P}$, Strydom A. Clinical aspects and biomarkers of Alzheimer's disease in Down syndrome. Free Radic Biol Med. 2018;114:3-9.

9. Doran E, Keator D, Head E, Phelan MJ, Kim R, Totoiu M, Barrio JR, Small GW, Potkin SG, Lott IT. Down syndrome, partial trisomy 21, and absence of Alzheimer's disease: the role of APP. J Alzheimers Dis. 2017;56:459-70

10. Prasher VP, Farrer MJ, Kessling AM, Fisher EM, West RJ, Barber PC, Butler AC. Molecular mapping of Alzheimer-type dementia in Down's syndrome. Ann Neurol. 1998;43:380-3.

11. Hardy J, Allsop D. Amyloid deposition as the central event in the aetiology of Alzheimer's disease. Trends Pharmacol Sci. 1991;12:383-8.

12. Selkoe DJ. The molecular pathology of Alzheimer's disease. Neuron. 1991;6: 487-98.

13. Margallo-Lana ML, Moore PB, Kay DW, Perry RH, Reid BE, Berney TP, Tyrer SP. Fifteen-year follow-up of 92 hospitalized adults with Down's syndrome: incidence of cognitive decline, its relationship to age and neuropathology. J Intellect Disabil Res. 2007;51:463-77.

14. Johnson KA, Schultz A, Betensky RA, Becker JA, Sepulcre J, Rentz D, Mormino E, Chhatwal J, Amariglio R, Papp K, et al. Tau positron emission tomographic imaging in aging and early Alzheimer disease. Ann Neurol. 2016;79:110-9.
15. Mattsson N, Andreasson U, Zetterberg H, Blennow K. Alzheimer's disease neuroimaging I. Association of plasma neurofilament light with neurodegeneration in patients with Alzheimer disease. JAMA Neurol. 2017; 74:557-66.

16. Strydom A, Heslegrave A, Startin CM, Mok KY, Hardy J, Groet J, Nizetic D, Zetterberg $\mathrm{H}$, Consortium L. Neurofilament light as a blood biomarker for neurodegeneration in Down syndrome. Alzheimers Res Ther. 2018;10:39.

17. Fortea J, Carmona-Iragui M, Benejam B, Fernandez S, Videla L, Barroeta I, Alcolea D, Pegueroles J, Munoz L, Belbin O, et al. Plasma and CSF biomarkers for the diagnosis of Alzheimer's disease in adults with Down syndrome: a cross-sectional study. Lancet Neurol. 2018;17:860-9.

18. Holmes C, Cunningham C, Zotova E, Woolford J, Dean C, Kerr S, Culliford D, Perry VH. Systemic inflammation and disease progression in Alzheimer disease. Neurology. 2009;73:768-74.

19. Holmes C, El-Okl M, Williams AL, Cunningham C, Wilcockson D, Perry VH. Systemic infection, interleukin 1beta, and cognitive decline in Alzheimer's disease. J Neurol Neurosurg Psychiatry. 2003;74:788-9.

20. Swardfager W, Lanctot K, Rothenburg L, Wong A, Cappell J, Herrmann N. A metaanalysis of cytokines in Alzheimer's disease. Biol Psychiatry. 2010;68:930-41.

21. Engelhart MJ, Geerlings MI, Meijer J, Kiliaan A, Ruitenberg A, van Swieten JC, Stijnen T, Hofman A, Witteman JC, Breteler MM. Inflammatory proteins in plasma and the risk of dementia: the Rotterdam study. Arch Neurol. 2004;61:668-72.

22. D'Anna L, Abu-Rumeileh S, Fabris M, Pistis C, Baldi A, Sanvilli N, Curcio F, Gigli GL, D'Anna S, Valente M. Serum interleukin-10 levels correlate with cerebrospinal fluid amyloid beta deposition in Alzheimer disease patients. Neurodegener Dis. 2017;17:227-34.

23. Harold D, Abraham R, Hollingworth P, Sims R, Gerrish A, Hamshere ML, Pahwa JS, Moskvina V, Dowzell K, Williams A, et al. Genome-wide association study identifies variants at CLU and PICALM associated with Alzheimer's disease. Nat Genet. 2009;41:1088-93.

24. Hollingworth P, Harold D, Sims R, Gerrish A, Lambert JC, Carrasquillo MM, Abraham R, Hamshere ML, Pahwa JS, Moskvina V, et al. Common variants at ABCA7, MS4A6A/MS4A4E, EPHA1, CD33 and CD2AP are associated with Alzheimer's disease. Nat Genet. 2011;43:429-35.

25. Lambert JC, Ibrahim-Verbaas CA, Harold D, Naj AC, Sims R, Bellenguez C, DeStafano AL, Bis JC, Beecham GW, Grenier-Boley B, et al. Meta-analysis of 74,046 individuals identifies 11 new susceptibility loci for Alzheimer's disease. Nat Genet. 2013:45:1452-8.

26. Jones L, Holmans PA, Hamshere ML, Harold D, Moskvina V, Ivanov D, Pocklington A, Abraham R, Hollingworth P, Sims R, et al. Genetic evidence implicates the immune system and cholesterol metabolism in the aetiology of Alzheimer's disease. PLoS One. 2010:5:e13950.

27. Conti E, Galimberti G, Piazza F, Raggi ME, Ferrarese C. Increased soluble APPalpha, Abeta 1-42, and anti-Abeta 1-42 antibodies in plasma from Down syndrome patients. Alzheimer Dis Assoc Disord. 2010;24:96-100.

28. Lee NC, Yang SY, Chieh JJ, Huang PT, Chang LM, Chiu YN, Huang AC, Chien YH, Hwu WL, Chiu MJ. Blood beta-amyloid and tau in Down syndrome: a comparison with Alzheimer's disease. Front Aging Neurosci. 2016;8:316.

29. Head E, Doran E, Nistor M, Hill M, Schmitt FA, Haier RJ, Lott IT. Plasma amyloidbeta as a function of age, level of intellectual disability, and presence of dementia in Down syndrome. J Alzheimers Dis. 2011;23:399-409.

30. Mehta PD, Capone G, Jewell A, Freedland RL. Increased amyloid beta protein levels in children and adolescents with Down syndrome. J Neurol Sci. 2007;254:22-7.

31. Iulita MF, Ower A, Barone C, Pentz R, Gubert P, Romano C, Cantarella RA, Elia F, Buono S, Recupero M, et al. An inflammatory and trophic disconnect biomarker profile revealed in Down syndrome plasma: relation to cognitive decline and longitudinal evaluation. Alzheimers Dement. 2016;12:1132-48.

32. Schupf N, Patel B, Silverman W, Zigman WB, Zhong N, Tycko B, Mehta PD, Mayeux R. Elevated plasma amyloid beta-peptide 1-42 and onset of dementia in adults with Down syndrome. Neurosci Lett. 2001;301:199-203.

33. Mehta PD, Dalton AJ, Mehta SP, Kim KS, Sersen EA, Wisniewski HM. Increased plasma amyloid beta protein 1-42 levels in Down syndrome. Neurosci Lett. 1998;241:13-6.

34. Mehta PD, Mehta SP, Fedor B, Patrick BA, Emmerling M, Dalton AJ. Plasma amyloid beta protein 1-42 levels are increased in old Down syndrome but not in young Down syndrome. Neurosci Lett. 2003;342:155-8.

35. Cavani S, Tamaoka A, Moretti A, Marinelli L, Angelini G, Di Stefano S, Piombo G, Cazzulo V, Matsuno S, Shoji S, et al. Plasma levels of amyloid beta 40 and 42 are independent from ApoE genotype and mental retardation in Down syndrome. Am J Med Genet. 2000;95:224-8. 
36. Matsubara E, Ghiso J, Frangione B, Amari M, Tomidokoro Y, Ikeda Y, Harigaya Y, Okamoto K, Shoji M. Lipoprotein-free amyloidogenic peptides in plasma are elevated in patients with sporadic Alzheimer's disease and Down's syndrome. Ann Neurol. 1999;45:537-41.

37. Tokuda T, Fukushima T, Ikeda S, Sekijima Y, Shoji S, Yanagisawa N, Tamaoka A. Plasma levels of amyloid beta proteins Abeta1-40 and Abeta1-42(43) are elevated in Down's syndrome. Ann Neurol. 1997;41:271-3.

38. Kasai $T$, Tatebe $H$, Kondo M, Ishii R, Ohmichi T, Yeung WTE, Morimoto M, Chiyonobu T, Terada N, Allsop D, et al. Increased levels of plasma total tau in adult Down syndrome. PLoS One. 2017:12:e0188802.

39. Kusters MA, Verstegen $\mathrm{RH}$, Gemen EF, de Vries E. Intrinsic defect of the immune system in children with Down syndrome: a review. Clin Exp Immunol. 2009;156:189-93

40. Goldacre MJ, Wotton CJ, Seagroatt V, Yeates D. Cancers and immune related diseases associated with Down's syndrome: a record linkage study. Arch Dis Child. 2004;89:1014-7.

41. Wilcock DM, Griffin WS. Down's syndrome, neuroinflammation, and Alzheimer neuropathogenesis. J Neuroinflammation. 2013;10:84.

42. Cetiner S, Demirhan O, Inal TC, Tastemir D, Sertdemir Y. Analysis of peripheral blood T-cell subsets, natural killer cells and serum levels of cytokines in children with Down syndrome. Int J Immunogenet. 2010;37:233-7.

43. Zaki ME, El-Bassyouni HT, Tosson AM, Youness E, Hussein J. Coenzyme Q10 and pro-inflammatory markers in children with Down syndrome: clinical and biochemical aspects. J Pediatr. 2017;93:100-4.

44. Corsi MM, Dogliotti G, Pedroni F, Palazzi E, Magni P, Chiappelli M, Licastro F. Plasma nerve growth factor (NGF) and inflammatory cytokines (IL-6 and MCP-1) in young and adult subjects with Down syndrome: an interesting pathway. Neuro Endocrinol Lett. 2006;27:773-8.

45. Nateghi Rostami M, Douraghi M, Miramin Mohammadi A, Nikmanesh B. Altered serum pro-inflammatory cytokines in children with Down's syndrome. Eur Cytokine Netw. 2012;23:64-7.

46. Zhang Y, Che M, Yuan J, Yu Y, Cao C, Qin XY, Cheng Y. Aberrations in circulating inflammatory cytokine levels in patients with Down syndrome: a meta-analysis. Oncotarget. 2017:8:84489-96.

47. Startin CM, Hamburg S, Hithersay R, Davies A, Rodger E, Aggarwal N, AlJanabi T, Strydom A. The LonDownS adult cognitive assessment to study cognitive abilities and decline in Down syndrome. Wellcome Open Res. 2016;1:11.

48. Westwood S, Baird AL, Hye A, Ashton NJ, Nevado-Holgado AJ, Anand SN, Liu B, Newby D, Bazenet C, Kiddle SJ, et al. Plasma protein biomarkers for the prediction of CSF amyloid and tau and [(18)F]-flutemetamol PET scan result. Front Aging Neurosci. 2018;10:409.

49. McKhann G, Drachman D, Folstein M, Katzman R, Price D, Stadlan EM. Clinical diagnosis of Alzheimer's disease: report of the NINCDS-ADRDA Work Group under the auspices of Department of Health and Human Services Task Force on Alzheimer's disease. Neurology. 1984;34:939-44.

50. Majbour NK, Chiasserini D, Vaikath NN, Eusebi P, Tokuda T, van de Berg W, Parnetti L, Calabresi P, El-Agnaf OM. Increased levels of CSF total but not oligomeric or phosphorylated forms of alpha-synuclein in patients diagnosed with probable Alzheimer's disease. Sci Rep. 2017;7:40263.

51. Alcolea D, Martinez-Lage P, Sanchez-Juan P, Olazaran J, Antunez C, Izagirre A, Ecay-Torres M, Estanga A, Clerigue M, Guisasola MC, et al. Amyloid precursor protein metabolism and inflammation markers in preclinical Alzheimer disease. Neurology. 2015;85:626-33.

52. Wiseman FK, Pulford L, Barkus C, Liao F, Portelius E, Webb R, ChavezGutierrez L, Cleverley K, Noy S, Sheppard O, et al. Trisomy of human chromosome 21 enhances amyloid-beta deposition independently of an extra copy of APP. Brain. 2018;141:2457-74.

53. Lambert JC, Schraen-Maschke S, Richard F, Fievet N, Rouaud O, Berr C, Dartigues JF, Tzourio C, Alperovitch A, Buee L, Amouyel P. Association of plasma amyloid beta with risk of dementia: the prospective Three-City Study. Neurology. 2009;73:847-53.

54. Fandos N, Perez-Grijalba V, Pesini P, Olmos S, Bossa M, Villemagne VL, Doecke J, Fowler C, Masters CL, Sarasa M, Group AR. Plasma amyloid beta $42 / 40$ ratios as biomarkers for amyloid beta cerebral deposition in cognitively normal individuals. Alzheimers Dement (Amst). 2017;8:179-87.

55. Nakamura A, Kaneko N, Villemagne VL, Kato T, Doecke J, Dore V, Fowler C, Li QX, Martins R, Rowe C, et al. High performance plasma amyloid-beta biomarkers for Alzheimer's disease. Nature. 2018;554:249-54.

56. Ovod V, Ramsey KN, Mawuenyega KG, Bollinger JG, Hicks T, Schneider T, Sullivan M, Paumier K, Holtzman DM, Morris JC, et al. Amyloid beta concentrations and stable isotope labeling kinetics of human plasma specific to central nervous system amyloidosis. Alzheimers Dement. 2017;13:841-9.

57. Janelidze S, Stomrud E, Palmqvist S, Zetterberg H, van Westen D, Jeromin A, Song L, Hanlon D, Tan Hehir CA, Baker D, et al. Plasma beta-amyloid in Alzheimer's disease and vascular disease. Sci Rep. 2016;6:26801.

58. Blennow K. A review of fluid biomarkers for Alzheimer's disease: moving from CSF to blood. Neurol Ther. 2017:6:15-24.

59. Buss L, Fisher E, Hardy J, Nizetic D, Groet J, Pulford L, Strydom A. Intracerebral haemorrhage in Down syndrome: protected or predisposed? F1000Res. 2016:5:876.

60. Jones EL, Hanney M, Francis PT, Ballard CG. Amyloid beta concentrations in older people with Down syndrome and dementia. Neurosci Lett. 2009;451:162-4.

61. Prasher VP, Sajith SG, Mehta P, Zigman WB, Schupf N. Plasma beta-amyloid and duration of Alzheimer's disease in adults with Down syndrome. Int J Geriatr Psychiatry. 2010;25:202-7.

62. Matsuoka Y, Andrews HF, Becker AG, Gray AJ, Mehta PD, Sano MC, Dalton AJ, Aisen PS. The relationship of plasma Abeta levels to dementia in aging individuals with Down syndrome. Alzheimer Dis Assoc Disord. 2009;23:315-8.

63. Schupf N, Patel B, Pang D, Zigman WB, Silverman W, Mehta PD, Mayeux R. Elevated plasma beta-amyloid peptide Abeta(42) levels, incident dementia, and mortality in Down syndrome. Arch Neurol. 2007;64:1007-13.

64. Rafii MS, Wishnek H, Brewer JB, Donohue MC, Ness S, Mobley WC, Aisen PS, Rissman RA. The Down syndrome biomarker initiative (DSBI) pilot: proof of concept for deep phenotyping of Alzheimer's disease biomarkers in Down syndrome. Front Behav Neurosci. 2015;9:239.

65. Matsubara E, Sekijima Y, Tokuda T, Urakami K, Amari M, Shizuka-Ikeda M, Tomidokoro Y, Ikeda M, Kawarabayashi T, Harigaya Y, et al. Soluble Abeta homeostasis in $\mathrm{AD}$ and DS: impairment of anti-amyloidogenic protection by lipoproteins. Neurobiol Aging. 2004;25:833-41.

66. Startin CM, Hamburg S, Hithersay R, Al-Janabi T, Mok KY, Hardy J, LonDownS Strydom A. Cognitive markers of preclinical and prodromal Alzheimer's disease in Down syndrome. Alzheimers Dement. 2019;15:245-57.

67. Coppus AM, Fekkes D, Verhoeven WM, Evenhuis HM, van Duijn CM. Neopterin and the risk of dementia in persons with Down syndrome. Neurosci Lett. 2009;458:60-4.

68. Zis P, Strydom A, Buckley D, Adekitan D, McHugh PC. Cognitive ability in Down syndrome and its relationship to urinary neopterin, a marker of activated cellular immunity. Neurosci Lett. 2017;636:254-7.

69. Dekker AD, Coppus AM, Vermeiren Y, Aerts T, van Duijn CM, Kremer BP, Naude PJ, Van Dam D, De Deyn PP. Serum MHPG strongly predicts conversion to Alzheimer's disease in behaviorally characterized subjects with Down syndrome. J Alzheimers Dis. 2015;43:871-91.

70. Landt J, Ball SL, Holland AJ, Hon J, Owen A, Treppner P, Herbert J. Age-related changes in plasma dehydroepiandrosterone levels in adults with Down's syndrome and the risk of dementia. J Neuroendocrinol. 2011;23:450-5.

71. Zis P, Dickinson M, Shende S, Walker Z, Strydom A. Oxidative stress and memory decline in adults with Down syndrome: longitudinal study. J Alzheimers Dis. 2012;31:277-83.

72. Zis P, McHugh P, McQuillin A, Pratico D, Dickinson M, Shende S, Walker Z, Strydom A. Memory decline in Down syndrome and its relationship to iPF2alpha, a urinary marker of oxidative stress. PLoS One. 2014;9:e97709.

73. Ashton NJ, Scholl M, Heurling K, Gkanatsiou E, Portelius E, Hoglund K, Brinkmalm G, Hye A, Blennow K, Zetterberg H. Update on biomarkers for amyloid pathology in Alzheimer's disease. Biomark Med. 2018;12:799-812.

74. Hamlett ED, Goetzl EJ, Ledreux A, Vasilevko V, Boger HA, LaRosa A, Clark D, Carroll SL, Carmona-Iragui M, Fortea J, et al. Neuronal exosomes reveal Alzheimer's disease biomarkers in Down syndrome. Alzheimers Dement. 2017;13:541-9.

75. Coppus AM, Schuur M, Vergeer J, Janssens AC, Oostra BA, Verbeek MM, van Duijn CM. Plasma beta amyloid and the risk of Alzheimer's disease in Down syndrome. Neurobiol Aging. 2012;33:1988-94.

76. Schupf N, Zigman WB, Tang MX, Pang D, Mayeux R, Mehta P, Silverman W. Change in plasma $A B$ peptides and onset of dementia in adults with Down syndrome. Neurology. 2010;75:1639-44. 